\title{
Editorial
}

\section{Water and Wastewater Treatment: Selected Topics}

\author{
Krzysztof Barbusiński ${ }^{1, *(D)}$ and Krzysztof Filipek ${ }^{2}$ D \\ 1 Department of Water and Wastewater Engineering, Silesian University of Technology, Konarskiego 18, \\ 44-100 Gliwice, Poland \\ 2 Advisory Company, Wróblewskiego 8/27, 41-106 Siemianowice Slaskie, Poland; k.filipek@fdkf.pl \\ * Correspondence: krzysztof.barbusinski@polsl.pl
}

check for updates

Citation: Barbusiński, K.; Filipek, K. Water and Wastewater Treatment: Selected Topics. Clean Technol. 2022, 4, 91-96. https://doi.org/10.3390/ cleantechnol4010007

Received: 29 January 2022

Accepted: 8 February 2022

Published: 14 February 2022

Publisher's Note: MDPI stays neutral with regard to jurisdictional claims in published maps and institutional affiliations.

Copyright: () 2022 by the authors Licensee MDPI, Basel, Switzerland. This article is an open access article distributed under the terms and conditions of the Creative Commons Attribution (CC BY) license (https:// creativecommons.org/licenses/by/ $4.0 /)$.
Currently, there is a real need for rapid progress and development in almost all industries and areas of human activity. In the field of wastewater treatment, the development of already existing technologies is clearly recognized. The main focus is on the development of new, innovative processes concerning not only the degradation of pollutants, but also the recovery of valuable raw materials from wastewater. It is strongly linked to carbon footprint reduction and it also refers to the recently discussed "water footprint".

Until recently, only "wasted water" was considered as wastewater, and the purpose of purification was to remove organic contaminants, as well as nitrogen and phosphorus substances, and additionally, from industrial wastewater, specific impurities. Nowadays, wastewater and sewage sludge are more frequently being recognized as sources of energy and valuable, most often being non-renewable resources. Such an approach is consistent with the assumptions of circular economy ideas that could be applied in wastewater treatment plants by means of energy production and its optimized consumption and the recovery of important raw materials, e.g., phosphorous, nitrogen, and water from wastewater and sludge. In the near future, it could also be possible to recover bioplastic materials (polyhydroxyalkanoates; PHAs) and produce "green" hydrogen (the fuel of the future). Therefore, nowadays, modern wastewater treatment plants should not be considered only as facilities protecting water ecosystems, but also as technological energy plants and objects to recover important raw materials.

Moreover, there are some new challenges to be met by the wastewater treatment plants, e.g., the removal of pharmaceuticals. Currently, the purification processes carried out in wastewater treatment plants are not adapted to remove impurities such as, e.g., endocrinedisrupting compounds (EDCs) and pharmaceutical and personal care products (PPCPs). Therefore, in the near future, it is necessary to modernize the technological systems of treatment plants and to use more effective treatment techniques, such as advanced oxidation processes (AOPs), membrane processes, adsorption, etc.

It is also important to introduce the above-mentioned advanced methods to facilitate the effective treatment of industrial wastewater and landfill leachate. The intensification of activities leading to the use of treated industrial wastewater for re-use as process water is particularly important.

The presented Special Issue includes publications to cover a comprehensive range of wastewater treatment technologies. It contains three scientific publications based on the obtained research results and two review publications. The published articles cover a wide range of topics, which confirms that the wastewater treatment technology has significant interdisciplinarity and it is a field where there is significant progress in the research and implementation of innovative scientific and technical solutions.

We provide a brief review of the papers published as follows:

Waste Ochre for Control of Phosphates and Sulfides in Digesters at Wastewater Treatment Plants with Enhanced Biological Phosphorus Removal 
Öfverström et al. [1] used waste ochre to optimize anaerobic sludge digestion. They demonstrated the potential for using waste ochre instead of commercially available iron to reduce the concentration of hydrogen sulfide in biogas production and to reduce the release of phosphate into a sludge liquor at WWTPs with enhanced biological phosphorus removal. Ochre $\left(\mathrm{Fe}_{2} \mathrm{O}_{3}\right)$ is a waste product from water treatment plants, based on ironcontaminated raw groundwater treatment. The authors used the ochre from the Antaviliai water treatment plant (Vilnius, Lithuania), which supplies drinking water to 250,000 people. The ochre had a total solids content (TS) of about $40 \%$, and $1 \mathrm{~g}$ TS of ochre contained approximately $350-400 \mathrm{mg} \mathrm{Fe}{ }^{3+}$. Batch and continuous pilot-scale tests were performed for the mesophilic digestion of primary and waste-activated sludge with different doses of ochre.

It has been shown that in order to prevent the inhibition of the methane production process, small doses of ochre should be applied continuously, and the dosing should be optimized in order to reduce extra sludge production. In batch tests, the dosing of ochre $\left(0.5 \mathrm{~g} \mathrm{Fe}^{3+} / \mathrm{L}\right.$ and $\left.1 \mathrm{~g} \mathrm{Fe}^{3+} / \mathrm{L}\right)$ showed no inhibition of biogas production. With the addition of ochre, the accumulated methane potentials in the reactors were $10-15 \%$ higher than the methane potential in the control reactor. During the batch test, the phosphate release was reduced by $29 \%$ and $57 \%$ for the low and high doses, respectively.

During the pilot scale experiment, an immediate drop from $2000 \mathrm{ppm}$ down to $570 \mathrm{ppm}$ of the $\mathrm{H}_{2} \mathrm{~S}$ concentration in the biogas was seen after the addition of ochre at two different doses: $2.5 \mathrm{~g} \mathrm{Fe}^{3+} / \mathrm{d}$ and $5 \mathrm{~g} \mathrm{Fe}^{3+} / \mathrm{d}$. However, the anaerobic conversion process in the reactor with the highest dose $\left(5 \mathrm{~g} \mathrm{Fe}^{3+} / \mathrm{d}\right)$ was inhibited by the ochre, resulting in high acetate concentrations (230-1700 mg/L). In a second pilot scale experiment, ochre was dosed continuously in smaller amounts $\left(1.5\right.$ and $\left.0.75 \mathrm{~g} \mathrm{Fe}^{3+} / \mathrm{d}\right)$ to avoid any inhibition processes during the phosphate precipitation. A reduction in phosphates in the sludge liquor (33\% and $66 \%$ for the low and high doses, respectively) was seen.

Hence, the described results show the technological phenomena related to the effective fermentation of sewage sludge and biogas production, as well as prevented the release of phosphorus from the sludge into post-fermentation leachate. The increased amount of phosphorus returned to the main technological line with these leachates is a clear signal for the operators of wastewater treatment plants to increase the doses of coagulants for chemical phosphorus precipitation from wastewater in order to meet the quality conditions of the discharged wastewater. In turn, hydrogen sulfide should be effectively removed from biogas because it is known to destroy the metal parts of cogeneration units used for the integrated production of heat and electricity in a sewage treatment plant. What is particularly worth noting is the use of a waste material (waste ocher), which is an example of introducing a circular economy in wastewater treatment plants.

Lomefloxacin-Occurrence in the German River Erft, Its Photo-Induced Elimination, and Assessment of Ecotoxicity Subsection

One of the modern tasks of wastewater treatment technology is the implementation of effective methods for the removal of pharmaceuticals and their metabolites in wastewater treatment plants. The technologies currently used in wastewater treatment plants are not adapted to the removal of this type of micro-pollutant. The processes of surface water treatment are not dedicated to removing these micro-pollutants as well. Thus, the pharmaceuticals and their metabolites could easily be transported into the natural water cycle, and in the form of drinking water could enter into human and animal organisms, which may cause a number of health problems [2]. Chemically, pharmaceuticals and their metabolites belong to various chemical groups and no uniform method of their removal or utilization has been developed so far. Currently, the Advanced Oxidation Processes (AOPs) are being used for this purpose, but it is most often carried out at the laboratory scale, because there are no legal regulations to oblige operators of the wastewater treatment plant to implement effective methods of pharmaceuticals removal. In addition, all the known methods do not remove individual pharmaceuticals with a similar efficiency [3]. 
An alternative to AOP processes can be, e.g., the use of potassium ferrate (VI) $\left(\mathrm{K}_{2} \mathrm{FeO}_{4}\right)$ as a strong oxidant [4].

Lomefloxacine is an antibiotic from the fluorchinolone group. These compounds, once they have reached the water reservoirs, are only scarcely decomposed by living microorganisms, and are able to survive for a long time to interact with the other water organisms [5]. The main threat of this situation refers to its continuous acting. Despite the low concentrations, at the level of $\mathrm{ng} / \mathrm{L}$, the long lasting supply with the discharged wastewater may cause real problems-the so-called pseudo-persistent compounds. The results of such a long-term exposure, however, at relatively low doses, almost non-observable and detected at very low concentrations only, could be statistically important and detected for the next many generations of the ecologically important organisms. It could also lead to constant and irreversible changes extending the adaptability of many animal species present in the streams, rivers and lakes.

Voigt et al. [6] in their publication researched a very interesting and current topic concerning the degradation of the antibiotic Lomefloxacin (LOM), detected in the German river Erft. The methodology of near and far ultraviolet (UVA, UVC) radiation was used as $\mathrm{AOPs}$ and examined in relation to $\mathrm{pH}$, water matrix, and catalysts. AOP catalysts, hydrogen peroxide and titanium dioxide were used. A chemical kinetics description revealed that UVC at pH 8-9 led to the fastest degradation of LOM. The catalysts hydrogen peroxide and titanium dioxide only had a limited influence on the degradation rate. Seven novel transformation products of the examined reactions were structurally identified by high-resolution higher-order mass spectrometry. The ecotoxicity of the novel and known compounds was assessed by quantitative structure-activity relationship (QSAR) analysis. In addition, the irradiation time-dependent minimum, and half-maximum inhibitory concentrations (MIC, IC50) of LOM solutions were clearly determined and suggested as ecotoxicological hazard indicators. From MIC and kinetic rate constants, the irradiation time required for compound and activity removal could be predicted.

In the Guest Editors' opinion, the reviewed paper should be distinguished as a crucial one in terms of water ecosystem protection from antibiotics. On the other hand, it is another reason to search the advanced methods to remove antibiotics from the wastewater, as was pointed out in the preface of this review.

Stimulating Nitrogen Biokinetics with the Addition of Hydrogen Peroxide to Secondary Effluent Biofiltration

Friedman et al. [7] used a tertiary wastewater treatment to remove $\mathrm{NH}_{4}{ }^{+}, \mathrm{NO}_{2}{ }^{-}$ and organic matter from secondary effluents in a pilot bio-filtration system assisted by adding hydrogen peroxide $\left(\mathrm{H}_{2} \mathrm{O}_{2}\right)$. The authors examined the impact of adding $\mathrm{H}_{2} \mathrm{O}_{2}$ as a supplemental oxygen source on the operational efficiency of a secondary effluent filtration system with biologically active media (biofiltration). The study examined the feasibility of stimulating microbial activity using $\mathrm{H}_{2} \mathrm{O}_{2}$ as a bio-specific and clean oxygen source that leaves no residuals in water and is advantageous upon aeration due to the solubility limitations of oxygen. The tertiary wastewater treatment system consisted of the following elements: wire filter $(500 \mu \mathrm{m}$ mesh), the coagulator-flocculator tank (with addition of polyaluminum chloride) and the biofilter bed with short HRT. The performance of a pilot bio-filtration system at a filtration velocity of $5-6 \mathrm{~m} / \mathrm{h}$ was enhanced by the addition of $\mathrm{H}_{2} \mathrm{O}_{2}$ for particle, organic matter, $\mathrm{NH}_{4}{ }^{+}$and $\mathrm{NO}_{2}{ }^{-}$removal. Hydrogen peroxide provided the oxygen demand for full nitrification. As a result, influent concentrations of $4.2 \mathrm{mg} / \mathrm{L}$ $\mathrm{N}-\mathrm{NH}_{4}{ }^{+}$and $0.65 \mathrm{mg} / \mathrm{L} \mathrm{N}^{-N}{ }_{2}{ }^{-}$were removed in the biofilter. The biofiltration without

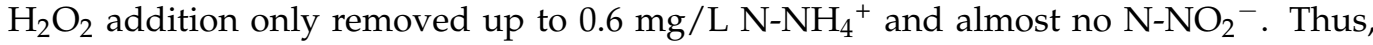
the system showed a significant removal of $\mathrm{NO}_{2}{ }^{-}$and $\mathrm{NH}_{4}{ }^{+}$when $\mathrm{H}_{2} \mathrm{O}_{2}$ was added in comparison to the control system (without $\mathrm{H}_{2} \mathrm{O}_{2}$ ). The authors also presented a model to describe the biokinetics of tertiary wastewater biofiltration systems with the addition of $\mathrm{H}_{2} \mathrm{O}_{2}$.

The research results presented in this publication could serve as a very good example of how to introduce a circular economy idea in the field of wastewater treatment technology. 
This Special Issue contains two review articles.

Removal of Odors (Mainly $\mathrm{H}_{2} \mathrm{~S}$ and $\mathrm{NH}_{3}$ ) Using Biological Treatment Methods

The air contamination by the odors and the volatile organic compounds (VOC) has been considered as a very current and serious problem all over the world. The odor nuisance and the health hazards are the main topics concerning both specialists and ordinary people. The VOC and odor compounds are the most prominent group in the atmosphere contamination factors. These compounds are known to be the precursors of photochemical oxidation, responsible for the formation of tropospheric ozone and smog, as a final result. They are counted as cancerogenic substances. The VOC and odors are formed as the by-products of the numerous industrial processes in, e.g., the varnish, wood, chemical, pharmaceutical, petrochemical and paper industries. They are also present in wastewater treatment plants and in the solid wastes processing plants. The emission of these compounds is relatively lower than nitrogen oxides (NOx); they show, however, a higher toxicity and reactivity, making them real threats to the environment and all human beings.

Facilities emitting the most persistent harmful gases belong to the municipal sector, including wastewater treatment plants, waste management plants or composting plants. The odor-producing compounds include:

- $\quad$ Sulfur compounds, i.e., hydrogen sulfide, thiols, sulfides, and alkyl disulfides;

- Nitrogen compounds, i.e., ammonia, and aliphatic amines;

- Organic compounds, including aldehydes, ketones, and fatty acids (phenol, cresol, butyric acid, acetic acid, and valeric acid).

The more and more active public awareness and strict formal environmental rules render the effective and innovative methods to eliminate the air contamination components highly awaited.

Barbusiński et al. [8] reviewed the available and most commonly used methods of gas deodorization. Comparing various, physical, chemical and biological, methods of odor removal, biological methods of pollution degradation undoubtedly have a clear advantage over the others - chemical and physical methods. This advantage is manifested mainly in ecological and economic terms. The possibility of using biological methods to remove $\mathrm{H}_{2} \mathrm{~S}$ and $\mathrm{NH}_{3}$, as the most common emissions by the municipal sector companies, was analyzed in terms of their removal efficiency. The method of bio-purification of air in biotrickling filters is more advantageous than the others, due to the high effectiveness of VOCs and odors degradation, lack of secondary pollutants, and economic aspects; it is a method that competes with the commonly used air purification method in biofilters.

A survey of the literature revealed that the biological methods of odor removal lead to high rates of the bio-purification of air, up to $95-99 \%$; moreover, their advantage is apparent innovation, primarily in the economic aspect as well as in terms of environmental friendliness. Therefore, it is necessary to develop and intensify processes based on the biological methods of odor removal, in order to implement them on the full industrial scale. A good example of the modern biotechnologies methods for odor removal is the Compact Trickle Bed Bioreactors with their potential versatility.

\section{Review of Methods for Assessing the Impact of WWTPs on the Natural Environment}

Bak et al. [9] reviewed methods of assessing the impact of wastewater treatment plants on the environment. This paper discusses the possible impact of WWTPs on the environment. Among other problems, such issues as energy consumption, noise and the formation of bioaerosols and odor nuisances were taken into account. Different ways of assessing the impact of wastewater treatment plants on the environment were described, taking into account the need to assess not only the technological process itself but also the building constructions in the course of operation. The results of various methods of the environmental impact assessment of wastewater treatment plants in selected countries were also compared. 
Any wastewater treatment plant exerts a certain environmental impact during the construction and operation stages. Therefore, there is a need to assess this impact not only at the design and construction phase, but also during the facility's operation. While such assessments are frequent at the investment planning stage, they tend to be neglected in the operational phase. On the other hand, control activities are carried out in the context of compliance with certain regulations concerning, for example, gas emissions.

Environmental management as a part of the operating management in wastewater treatment plants (WWTPs) could be a basis for implementing the Deming cycle (a concept of quality management consisting of continuous improvement taking place in four successive stages: planning, execution, checking, and improvement), and thus the constant improvement of the mitigation of the environmental impact. The correct diagnosis of the current operating state of the WWTPs, the identification of aspects that may have a measurable impact on the environment, and the impact assessment are key factors. The suggested direction of development to assess the environmental impact of wastewater treatment plants is the improvement of the LCA technique. It could be supported by the implementation of environmental management systems, with the supplementation of these actions through green building certification. Only a holistic approach to the issue will enable all the environmental aspects to be taken into account and thus contribute to maximizing the subsequent environmental benefits. It is also advisable, if possible, to undertake necessary steps to develop and implement a unified method of assessing the impact of sewage treatment plants on the environment. Parallel to this, some activities that encourage and stimulate the uptake of such challenges should be introduced. As a consequence, the processes carried out in wastewater treatment plants will become even more "clean", and the treatment plants themselves will become more environmentally friendly. Hence, the introduction of circular economy solutions in wastewater treatment plants is also of great importance.

Despite the relatively few articles in this Special Issue, it should be noted that these publications cover a very wide range of relevant issues and challenges in the field of wastewater treatment technology, as was pointed out earlier. This proves the important role this Special Edition plays in understanding the directions of further development of wastewater treatment technology.

Author Contributions: K.B. and K.F. contributed equally to this work. All authors have read and agreed to the published version of the manuscript.

Funding: This research received no external funding.

Institutional Review Board Statement: Not applicable.

Informed Consent Statement: Not applicable.

Acknowledgments: The task of editing articles for this Special Issue was a real pleasure and rewarding for us. We would also like to thank the Clean Technologies team and the reviewers for their technical and substantive effort and contribution.

Conflicts of Interest: The authors declare no conflict of interest.

\section{References}

1. Öfverström, S.; Davidsson, Å.; Haghighatafshar, S.; Kjerstadius, H.; la Cour Jansen, J. Waste Ochre for Control of Phosphates and Sulfides in Digesters at Wastewater Treatment Plants with Enhanced Biological Phosphorus Removal. Clean Technol. 2020, 2, 8. [CrossRef]

2. Huber, M.M.; Canonica, S.; Park, G.; von Gunten, U. Oxidation of pharmaceuticals during ozonation and advanced oxidation processes. Environ. Sci. Technol. 2003, 37, 1016-1024. [CrossRef] [PubMed]

3. Sharma, V.K.; Mishra, S.M.; Ray, A.K. Kinetic assessment of the potassium ferrate (VI) oxidation of antibacterial drug sulfamethoxazole. Chemosphere 2006, 62, 128-134. [CrossRef] [PubMed]

4. Kliś, S.; Barbusiński, K.; Thomas, M.; Mochnacka, A. Application of Potassium Ferrate (VI) in the Treatment of Selected Water and Wastewater Pollutants-Short Review. Archit. Civil. Eng. Environ. 2020, 1, 129-138. [CrossRef] 
5. Bielińska, M.; Nałęcz-Jawecki, G. Pharmaceuticals in the Environment. I: Evaluation of Toxicity of Three Fluoroquinolones to Duckweed Lemna Minor. Biul. Wydz. Farm. WUM 2009, 4, 24-30. Available online: http://biuletynfarmacji.wum.edu.pl/0904 Jawecki/Jawecki.pdf (accessed on 24 January 2022). (In Polish)

6. Voigt, M.; Hentschel, B.; Theiss, N.; Savelsberg, C.; Bartels, I.; Nickisch-Hartfiel, A.; Jaeger, M. Lomefloxacin-Occurrence in the German River Erft, Its Photo-Induced Elimination, and Assessment of Ecotoxicity. Clean Technol. 2020, 2, 6. [CrossRef]

7. Friedman, L.; Mamane, H.; Chandran, K.; Jekel, M.; Cikurel, H.; Hübner, U.; Elgart, M.; Dagan, S.; Santo-Domingo, J.; Avisar, D. Stimulating Nitrogen Biokinetics with the Addition of Hydrogen Peroxide to Secondary Effluent Biofiltration. Clean Technol. 2020, 2, 5. [CrossRef]

8. Barbusiński, K.; Parzentna-Gabor, A.; Kasperczyk, A. Removal of Odors (Mainly $\mathrm{H}_{2} \mathrm{~S}$ and $\mathrm{NH}_{3}$ ) Using Biological Treatment Methods. Clean Technol. 2021, 3, 9. [CrossRef]

9. Bak, J.; Barbusiński, K.; Thomas, T. Review of Methods for Assessing the Impact of WWTPs on the Natural Environment. Clean Technol. 2021, 3, 7. [CrossRef] 